\title{
Clinical presentation of childhood leukaemia: a systematic review and meta-analysis
}

\author{
Rachel T Clarke, ${ }^{1}$ Ann Van den Bruel, ${ }_{1}^{1}$ Clare Bankhead, ${ }^{1}$ Christopher D Mitchell, ${ }^{2}$ \\ Bob Phillips, ${ }^{3}$ Matthew J Thompson ${ }^{1,4}$
}

\begin{abstract}
- Additional material is published online only. To view please visit the journal online (http://dx.doi.org/10.1136/ archdischild-2016-311251).

${ }^{1}$ Department of Primary Care Health Sciences, University of Oxford, Oxford, UK

${ }^{2}$ Department of Paediatric Oncology/Haematology, Children's Hospital, John Radcliffe, Oxford, UK ${ }^{3}$ Department of Paediatric Oncology/Haematology, Leeds General Infirmary, Leeds, UK

${ }^{4}$ Department of Family Medicine, University of Washington, Seattle, USA
\end{abstract}

\section{Correspondence to}

Dr Rachel Clarke, Department of Primary Care Health

Sciences, University of Oxford, Oxford OX3 1BN, UK ; rtsclarke@gmail.com

Received 18 May 2016 Accepted 17 July 2016

\section{SLinked}

- http://dx.doi.org/10.1136/ archdischild-2015-308731

\section{CrossMark}

To cite: Clarke RT, Van den Bruel A, Bankhead C, et al. Arch Dis Child

2016;101:894-901.

\section{ABSTRACT}

Objective Leukaemia is the most common cancer of childhood, accounting for a third of cases. In order to assist clinicians in its early detection, we systematically reviewed all existing data on its clinical presentation and estimated the frequency of signs and symptoms presenting at or prior to diagnosis.

Design We searched MEDLINE and EMBASE for all studies describing presenting features of leukaemia in children (0-18 years) without date or language restriction, and, when appropriate, meta-analysed data from the included studies.

Results We screened 12303 abstracts for eligibility and included 33 studies $(n=3084)$ in the analysis. All were cohort studies without control groups. 95 presenting signs and symptoms were identified and ranked according to frequency. Five features were present in $>50 \%$ of children: hepatomegaly $(64 \%)$, splenomegaly (61\%), pallor (54\%), fever (53\%) and bruising (52\%). An additional eight features were present in a third to a half of children: recurrent infections (49\%), fatigue (46\%), limb pain (43\%), hepatosplenomegaly $(42 \%)$, bruising/petechiae (42\%), lymphadenopathy (41\%), bleeding tendency (38\%) and rash (35\%). $6 \%$ of children were asymptomatic on diagnosis.

Conclusions Over $50 \%$ of children with leukaemia have palpable livers, palpable spleens, pallor, fever or bruising on diagnosis. Abdominal symptoms such as anorexia, weight loss, abdominal pain and abdominal distension are common. Musculoskeletal symptoms such as limp and joint pain also feature prominently. Children with unexplained illness require a thorough history and focused clinical examination, which should include abdominal palpation, palpation for lymphadenopathy and careful scrutiny of the skin. Occurrence of multiple symptoms and signs should alert clinicians to possible leukaemia.

\section{INTRODUCTION}

In developed countries, cancer causes more childhood deaths than any other serious illness, including meningitis. ${ }^{1}$ Leukaemia is the most common malignancy of childhood, with an annual incidence of nearly 4000 in the USA and 450 in the UK, and is responsible for a third of childhood cancer deaths. $^{2}{ }^{3}$ Yet paediatric leukaemia is a lowprevalence disease in primary care, emergency departments and general paediatrics settings. A general practitioner, for example, is likely to encounter a child with cancer only once every 20 years. $^{4}$ The early presentation of paediatric leukaemia, with non-specific symptoms often

\section{What is already known on this topic?}

Serious illnesses such as cancer are rare in children in primary care (about 1 in 200 children) and are easily missed.

- Leukaemia is the most common cancer of childhood, with 4000 new cases annually in the USA and 450 in the UK.

\section{What this study adds?}

- Over $50 \%$ of children with leukaemia have palpable livers, palpable spleens, pallor, fever or bruising on diagnosis.

- Abdominal symptoms are not typically included in national cancer guidelines for identifying children with leukaemia, yet are present in 29\% (anorexia/weight loss), 12\% (abdominal pain) and $11 \%$ (abdominal distension) of children, respectively.

- Important common musculoskeletal and bleeding manifestations are also omitted, such as mucosal bleeding (25\%), joint pain (11\%) and $\operatorname{limp}(15 \%)$.

mimicking the common, self-limiting illnesses, complicates the diagnostic challenge faced by frontline clinicians. ${ }^{5} 6$

Improving the early diagnosis of cancer is a key priority for many health services. The UK's National Health Service Cancer Plan, for example, stipulates that all patients with suspected cancer, including children, should be seen by a specialist within two weeks of referral. ${ }^{7}$ Subsequent guidance from the National Institute for Health and Care Excellence (NICE) details a range of specific signs and symptoms that should alert clinicians to consider cancer in children and, in the case of leukaemia, take blood or immediately refer. ${ }^{5}$ Despite these attempts, the vast majority of cancers in children are still not diagnosed via the 2 -week urgent referral pathway. In one recent study, $98 \%$ of childhood cancers in the UK were identified by other routes, such as direct presentations to emergency departments or non-urgent hospital referrals from primary care. ${ }^{8}$

In order to improve our understanding of the early presentation of paediatric leukaemia, we aimed to systematically identify and collate all 
existing data on its presenting signs and symptoms at, or before, the point of diagnosis.

\section{METHOD}

\section{Search strategy}

We searched MEDLINE and EMBASE from inception to December 2014 using a combination of subject headings and free text incorporating the terms 'leukaemia' and 'diagnosis', and limited to infants, children and adolescents. Reference lists of included studies were also searched for potentially relevant studies. No language restrictions were applied. The complete search strategy is detailed online (see online supplementary appendix eSearch).

\section{Study selection}

We considered for selection all primary research studies, either retrospective or prospective, of any study design (eg, cohort), describing the frequency of signs and symptoms at time of diagnosis for a minimum of 10 children ( $0-18$ years) with any type of leukaemia. Duplicate studies were removed. Studies that selected cases based on the presence of only certain clinical features of leukaemia (eg, only musculoskeletal or gastrointestinal manifestations) were excluded to avoid giving disproportionate weight to those features in the data synthesis. We also excluded studies that reported data on both adults and children, but where we were unable to extract the paediatric data. Any uncertainties regarding studies selection were discussed between the authors.

One researcher (RTC) screened titles and abstracts of all papers, excluding clearly irrelevant studies. Two researchers (RTC and MJT) independently reviewed the full text of remaining papers to assess eligibility.

\section{Quality assessment}

Once we had assembled a shortlist of studies eligible for potential inclusion using the criteria above, two reviewers (RTC and MJT) independently assessed the risk of bias in these studies' results to ensure that only those studies with an acceptable risk of bias were included in this review (see online supplementary eTable1). There is no single, well-validated quality checklist for assessing retrospective cohort studies, and so we constructed a checklist based on relevant items from the MOOSE (metaanalysis of obeservational studies in epidemiology) reporting guideline for observational studies, ${ }^{9}$ the STROBE (strengthening the reporting of observational studies in epidemiology) reporting guideline for cohort studies, ${ }^{10}$ the Newcastle-Ottawa scale for non-randomised studies ${ }^{11}$ and CASP (critical appraisal skills programme) guidelines for case-control and cohort studies. ${ }^{12} 13$

Quality was assessed as 'acceptable' or 'unacceptable' in three domains: definition of leukaemia, selection of cases and methods for extracting data on included cases. 'Acceptable' for case definition required cases to be defined according to bone marrow findings. 'Acceptable' for case selection required at least two of participants' baseline characteristics clearly documented; characteristics of cases representative of children with that type of leukaemia (ie, the age and sex distribution of cases matched the known epidemiology of paediatric leukaemias); and the sample comprising all consecutive cases over the study period or, if non-consecutive, reasons for omission of cases documented. 'Acceptable' for data extraction required use of a standardised data collection proforma and/or the objective measurement of signs (eg, ultrasound confirmation of suspected organomegaly). Disagreements between the two reviewers were discussed with a third reviewer (AVDB). Only studies considered by all reviewers to pass in two or more domains were included in this review.

\section{Data extraction}

Data were extracted from included studies by one reviewer (RTC) using a standardised proforma and checked by a second reviewer (MJT). We extracted study characteristics including period of study, number and type of centres, study design, recruitment methods, sample size and age of children. Presenting signs and symptoms were recorded as described in each study, and numbers of children presenting with each feature noted. When a symptom or sign was not recorded in a study, no assumption was made about whether or not that feature had occurred in that population (ie, we did not assume that absence of recording was equivalent to absence of that feature). Authors cross-checked each others' data extraction to ensure accuracy. We did not contact authors of included papers for missing information.

\section{Statistical analysis}

We used STATA V.11.1 to calculate simple proportions and SEs of proportions for each presenting feature in each included study. Where considered clinically appropriate, features that the authors considered similar were aggregated (eg, 'petechiae', 'purpura' and 'petechiae/purpura' were combined into a single category, 'petechiae/purpura'). Features were not aggregated when it was not clinically sensible or when they were reported with insufficient clarity to avoid possible double counting.

We calculated pooled proportions of children presenting with each feature using the metan command. Anticipating high heterogeneity between included studies, we performed randomeffects meta-analysis using the DerSimonian and Laird method and standard methods to calculate $\mathrm{I}^{2}$ as an estimate of the heterogeneity. In addition, we conducted three a priori subgroup analyses to explore reasons for heterogeneity and generate new hypotheses: (1) type of leukaemia; (2) year of publication and (3) income status of the country in which the study was performed, as defined by the Organisation for Economic Cooperation and Development criteria at the time the study was conducted. We conducted subgroup analyses based on type of leukaemia, country income level and publication date of study as, based on the existing literature, we felt that these might plausibly affect the speed of presentation of children, accessibility of health, care and changes in health-seeking behaviour, as well as the possibility of different clinical features depending on leukaemia type. We used exactly the same technique, DerSimonian and Laird, as for the main analyses.

\section{RESULTS}

\section{Search results}

After removal of duplicates, we identified 12303 papers. We excluded 11889 after screening titles and abstracts, and a further 381 after full-text assessment (figure 1). Reference lists of included studies did not yield additional eligible studies. There were no differences between authors regarding whether a particular study should be included.

\section{Characteristics of included studies}

Thirty-five studies met the eligibility criteria and were considered for inclusion, with two of these being excluded on quality grounds, as detailed below (see online supplementary appendix eTable1). The 33 included studies ${ }^{14-42}$ were conducted in 21 countries and described presenting symptoms and signs in a total of 3084 children (table 1). All were retrospective cohorts 
Figure 1 Flow chart for selection of studies.

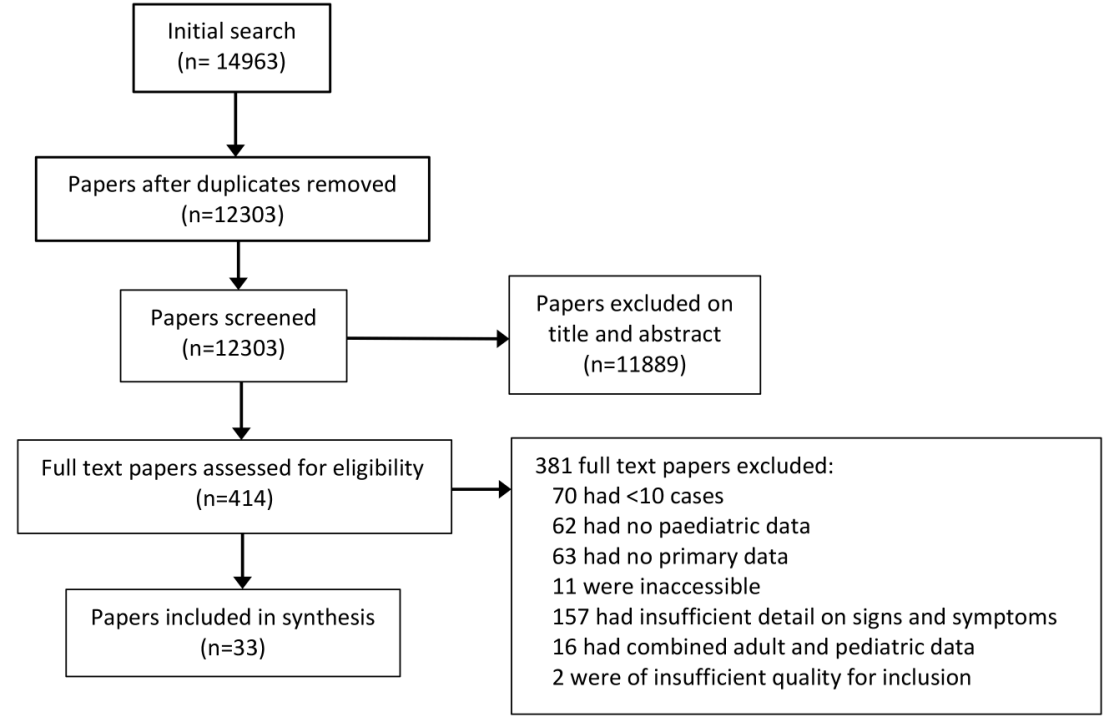

of between 10 and 406 participants, and none compared cases with controls.

The majority of studies $(n=26)$ identified cases from medical records alone; others also used national and regional registries of childhood leukaemias $(n=4)$, death certificates $(n=2)$, pathology reports $(n=1)$, clinical trial data $(n=1)$ and primary care records $(n=1)$. All 33 studies extracted data from written hospital records. One study also obtained data from primary care records, ${ }^{41}$ and another supplemented hospital records with data from a patient and/or parent-completed questionnaire. ${ }^{42}$

\section{Risk of bias of included studies}

All included studies defined cases using bone marrow criteria and clearly documented participants' baseline characteristics such as age and sex, which were consistent with the known epidemiology of paediatric leukaemias (see online supplementary appendix eTable1). Only 13 studies (39\%) included all consecutive cases within the study period, with a further 3 studies $(9 \%)$ describing why a proportion of potentially eligible cases were excluded. In the remaining 17 studies (4\%), the proportion of consecutive cases included was unclear.

One weakness of the included studies was lack of clarity about how the list of clinical features of leukaemia was generated and at which point in the diagnostic pathway clinical features were recorded. Fifteen studies explicitly stated that they reported signs and symptoms occurring 'at diagnosis', while two studies also reported symptoms from the point of symptom onset through to diagnosis. The remaining 16 studies were unclear as to whether the symptoms reported occurred at and/or prior to diagnosis.

\section{Pooled frequencies of symptoms and signs from meta-analysis}

The number of different signs and symptoms reported in individual studies ranged from 6 to 23 (median=11). Overall, 95 separate signs and symptoms were reported. We were able to aggregate 15 features into 6 overarching categories. These were petechiae/purpura (category derived from 'petechiae', 'purpura' and 'petechiae/purpura'), mucosal bleeding (including 'mucosal bleeding' and 'bleeding gums'), anorexia/weight loss (including 'anorexia', 'weight loss' and 'anorexia/weight loss'), weakness/ fatigue (including 'weakness', 'fatigue', 'weakness/fatigue'), malaise/fatigue (including 'malaise' and 'malaise/fatigue') and infections (including 'infection' and 'recurrent infections').

In total, 55 out of a possible 86 meta-analyses were conducted. For the remaining 31 features, meta-analysis was not required since the features were each present on only one study. The high heterogeneity $\left(\mathrm{I}^{2}\right)$ statistics in the meta-analyses (usually $>90 \%$ ) indicated that the degree of heterogeneity between studies was greater than that expected by chance alone and confirmed the appropriateness of random-effects metaanalysis to generate pooled proportions (figure 2).

The 36 features that were present in $\geq 10 \%$ of children are shown in figure 2 . We grouped these features into seven distinct clinical categories according to main underlying pathological process or body system affected: infiltrative, haemorrhagic, infective, systemic, musculoskeletal, gastrointestinal and cutaneous. The most common infiltrative symptoms were hepatomegaly (64\%) and splenomegaly (61\%). Bruising, the most common haemorrhagic symptom, occurred in $52 \%$ of children. Fever (53\%) was the most common infective symptom, and the most prominent musculoskeletal features were limb pain (43\%) and bone pain (26\%). Systemic features such as pallor (54\%) and fatigue $(46 \%)$ were also common. Finally, the most common gastrointestinal feature, anorexia/weight loss (29\%), was present in almost a third of children. Those features reported in a third or more of children are summarised in table 2, while those reported in $<10 \%$ of children are included in online supplementary appendix eTable 2 .

There were no data on the frequencies of combinations of symptoms, nor any data from control children. Nor was it possible to extract data on the timing of specific features, such as which presented first and last.

\section{Subgroup analyses}

There were 14 specific features for which it was possible to calculate presenting frequencies across the subgroups 'acute' and 'chronic' leukaemia (figure 3). Certain features of acute illness, such as fever, were more common in acute leukaemia $(62 \%$, CI 51 to 73 ) than chronic leukaemia (31\%, CI 13 to 49 ), whereas certain more progressive, infiltrative features, such as splenomegaly, were more prominent in chronic leukaemia $(77 \%$, CI 62 to 92 ) than acute $(56 \%$, CI 40 to 73$)$. Studies from highincome settings also showed a greater prevalence of splenomegaly $(76 \%$, CI 67 to 85$)$ compared with that in 
Table 1 Characteristics of included studies

\begin{tabular}{|c|c|c|c|c|c|c|c|}
\hline \multirow[b]{2}{*}{ Author } & \multirow[b]{2}{*}{ Country } & \multirow[b]{2}{*}{ Period of study } & \multirow[b]{2}{*}{ Source of data } & \multirow[b]{2}{*}{ Sample size } & \multicolumn{3}{|c|}{ Age (years) } \\
\hline & & & & & Median & Mean & Range \\
\hline \multicolumn{8}{|l|}{ All leukaemias combined } \\
\hline Das et $a l^{43}$ & India & 1961-1972 & Hospital records* & 69 & $\mathrm{n} / \mathrm{a}$ & $\mathrm{n} / \mathrm{a}$ & $\mathrm{n} / \mathrm{a}$ \\
\hline Garcia Calatayud et al ${ }^{25}$ & Spain & 1995-2000 & Hospital records* & 29 & $\mathrm{n} / \mathrm{a}$ & $\mathrm{n} / \mathrm{a}$ & $\mathrm{n} / \mathrm{a}$ \\
\hline Hasanbegovic $^{26}$ & Bosnia & 1997-2003 & Hospital records* & 130 & 6.3 & $\mathrm{n} / \mathrm{a}$ & $\mathrm{n} / \mathrm{a}$ \\
\hline Karimi $^{28}$ & Iran & 1997-2002 & Hospital recordst & 280 & $\mathrm{n} / \mathrm{a}$ & $\mathrm{n} / \mathrm{a}$ & $\mathrm{n} / \mathrm{a}$ \\
\hline La Grutta et a ${ }^{30}$ & Italy & 1960-1978 & Hospital records* & 334 & 3 & 6.1 & $0-15$ \\
\hline Meighan $^{33}$ & Canada & 1948-1960 & $\begin{array}{l}\text { (a) Saskatchewan Cancer Commission records } \\
\text { (b) Hospital records } \\
\text { (c) Death certificates } \\
\text { (d) Pathology reports } \ddagger\end{array}$ & 106 & $\mathrm{n} / \mathrm{a}$ & $\mathrm{n} / \mathrm{a}$ & $\mathrm{n} / \mathrm{a}$ \\
\hline Meighan $^{32}$ & USA & 1950-1961 & $\begin{array}{l}\text { (a) Hospital records } \\
\text { (b) Death certificates } \neq\end{array}$ & 258 & 3.0 & $\mathrm{n} / \mathrm{a}$ & $0-14$ \\
\hline Rajarajeswari and Viswanathan ${ }^{37}$ & India & 1968-1977 & Hospital records* & 100 & $\mathrm{n} / \mathrm{a}$ & $\mathrm{n} / \mathrm{a}$ & $0-11$ \\
\hline Thulesius et $a l^{41}$ & Sweden & 1984-1995 & $\begin{array}{l}\text { (a) Regional Tumour Registry } \\
\text { (b) Hospital records } \\
\text { (c) Primary care records }{ }^{\ddagger}\end{array}$ & 25 & $\mathrm{n} / \mathrm{a}$ & 6.6 & $\mathrm{n} / \mathrm{a}$ \\
\hline Zahid et $a l^{42}$ & Pakistan & 1992-1994 & $\begin{array}{l}\text { (a) Hospital records } \\
\text { (b) Parent/patient-completed data } \\
\text { extraction form* }\end{array}$ & 62 & n/a & 8.1 & $\mathrm{n} / \mathrm{a}$ \\
\hline \multicolumn{8}{|l|}{ All acute leukaemias combined } \\
\hline Biswas et al ${ }^{18}$ & India & 2003-2005 & Hospital records* & 75 & $\mathrm{n} / \mathrm{a}$ & n/a & $1.8-14$ \\
\hline Hassan et $a l^{27}$ & India & 1987-1990 & Hospital records* & 45 & $\mathrm{n} / \mathrm{a}$ & $\mathrm{n} / \mathrm{a}$ & $\mathrm{n} / \mathrm{a}$ \\
\hline Robazzi et al ${ }^{39}$ & Brazil & 1995-2004 & Hospital records* & 406 & 6.2 & $\mathrm{n} / \mathrm{a}$ & $0.8-15$ \\
\hline Sinigaglia et $a l^{40}$ & Italy & 1984-1999 & Hospital records* & 122 & 5.6 & 6.6 & $0.7-17.3$ \\
\hline \multicolumn{8}{|l|}{ Acute lymphoid leukaemias } \\
\hline \multicolumn{8}{|l|}{ (i) Acute lymphocytic leukaemia } \\
\hline Atay et $a l^{16}$ & Turkey & 1993-2000 & Hospital records* & 34 & $\mathrm{n} / \mathrm{a}$ & 5.8 & $2-14$ \\
\hline Bernbeck et $a l^{17}$ & Germany & 1995-2004 & Hospital records* & 189 & 5.8 & n/a & $0.1-17.8$ \\
\hline Drozynsky et $a l^{44}$ & Poland & 1996-2001 & Hospital records* & 30 & 5 & 7.5 & $3-17$ \\
\hline Ma et $a \beta^{31}$ & Hong Kong & 1985-1994 & Hospital records* & 73 & 4.3 & $\mathrm{n} / \mathrm{a}$ & $0.4-14.2$ \\
\hline \multicolumn{8}{|l|}{ Acute myeloid leukaemias } \\
\hline \multicolumn{8}{|l|}{ (i) Acute myeloid leukaemia } \\
\hline Choi and Simone ${ }^{23}$ & USA & 1962-1973 & Hospital records* & 171 & 8 & $\mathrm{n} / \mathrm{a}$ & $0-22$ \\
\hline Klinowska et $a l^{29}$ & Poland & 1955-1969 & Hospital records* & 106 & $\mathrm{n} / \mathrm{a}$ & $\mathrm{n} / \mathrm{a}$ & $\mathrm{n} / \mathrm{a}$ \\
\hline Revesz et $a l^{38}$ & Hungary & 1971-1982 & Leukemia Working Party Hospital records§ & 123 & $\mathrm{n} / \mathrm{a}$ & $\mathrm{n} / \mathrm{a}$ & $\mathrm{n} / \mathrm{a}$ \\
\hline \multicolumn{8}{|l|}{ (ii) Acute promyelocytic leukaemia } \\
\hline Chan et $a l^{20}$ & USA & $1974-1980$ & Hospital records $\emptyset$ & 16 & 8.5 & $\mathrm{n} / \mathrm{a}$ & $2-17$ \\
\hline Da Costa Moraes et al ${ }^{24}$ & Brazil & $2002-2006$ & Hospital records* & 15 & 10 & $\mathrm{n} / \mathrm{a}$ & $4-17$ \\
\hline \multicolumn{8}{|l|}{ (iii) Acute megakaryocytic leukaemia } \\
\hline Paredes-Aguiler et $a l^{36}$ & Mexico & 1990-2002 & Hospital records* & 29 & 6.5 & $\mathrm{n} / \mathrm{a}$ & $0.3-16$ \\
\hline \multicolumn{8}{|l|}{ Chronic myeloid leukaemias } \\
\hline \multicolumn{8}{|l|}{ (i) Chronic myeloid leukaemia } \\
\hline Castro-Malaspina et al ${ }^{19}$ & France & 1963-1976 & Hospital records* & 39 & n/a & n/a & $2-16$ \\
\hline Chang et $a l^{21}$ & Taiwan & $1976-2001$ & Hospital records* & 47 & $\mathrm{n} / \mathrm{a}$ & n/a & $2.7-17$ \\
\hline Liu et $a l^{45}$ & China & 1994-2009 & Hospital records* & 12 & 6.4 & $\mathrm{n} / \mathrm{a}$ & $1.2-11$ \\
\hline Millot et al ${ }^{34}$ & France & 1991-2003 & $\begin{array}{l}\text { (a) Clinical trial data } \\
\text { (b) Hospital records** }\end{array}$ & 40 & 12.5 & $\mathrm{n} / \mathrm{a}$ & $1-18$ \\
\hline \multicolumn{8}{|l|}{ (ii) Juvenile myelomonocytic leukaemia } \\
\hline Arico et $a l^{14}$ & Italy & 1983-1992 & National Registry for JCML§ & 22 & 1.3 & $\mathrm{n} / \mathrm{a}$ & $0-4$ \\
\hline Arya et $a l^{16}$ & India & 1980-1991 & Hospital records* & 10 & n/a & 1.7 & $0.3-4.5$ \\
\hline Castro-Malaspina et al ${ }^{19}$ & France & 1954-1977 & Hospital records* & 38 & $\mathrm{n} / \mathrm{a}$ & $\mathrm{n} / \mathrm{a}$ & $0.3-5.5$ \\
\hline Chang et $a l^{22}$ & Taiwan & 1978-2001 & Hospital records* & 16 & $\mathrm{n} / \mathrm{a}$ & 2.5 & $0.7-4.0$ \\
\hline Owen et $a l^{35}$ & UK & 1971-1986 & $\begin{array}{l}\text { (a) Childhood Cancer Research Group records } \\
\text { (b) Hospital records§ }\end{array}$ & 33 & 2.2 & $\mathrm{n} / \mathrm{a}$ & $0.3-8.8$ \\
\hline
\end{tabular}

*One hospital. †Three hospitals. ‡Regionwide. §Nationwide. १Two hospitals. ${ }^{* \star S i x t e e n ~ h o s p i t a l s . ~ N / A, ~ n o t ~ a p p l i c a b l e . ~}$ 


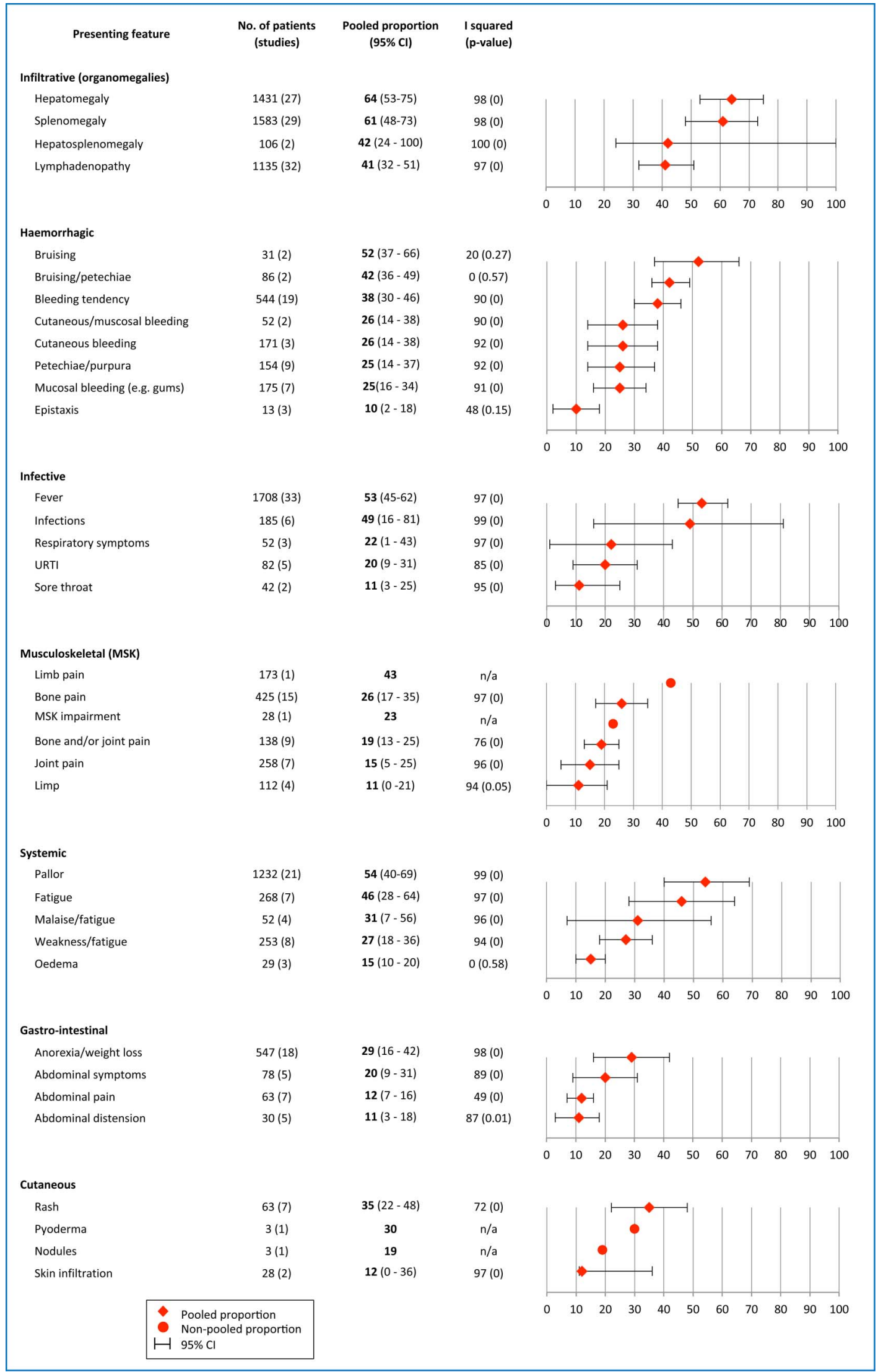

Figure 2 Frequency of signs and symptoms present in $\geq 10 \%$ in children with leukaemia. URTI, upper respiratory tract infection. 
moderate-income/low-income settings (51\%, CI 36 to 64$)$. Conversely, other clinical features, such as fever, pallor and anorexia/weight loss, were more common in low-income/ moderate-income settings (70\%, CI 62 to 77, 73\%, 15 to 52, $43 \%$, CI 14 to 73 , respectively) than in high-income settings (37\%, CI 26 to $47,34 \%$, CI 15 to $52,22 \%$, CI 15 to 28 , respectively). All three of the planned subgroup analyses (ie, by leukaemia type, publication date and income status of country) exhibited high heterogeneity, and most $\mathrm{I}^{2}$ statistics were $>90 \%$ (online supplementary appendix eTable3). We cannot exclude the difference in prevalence being due to confounding factors other than the subgroup criteria we selected.

\section{DISCUSSION}

Principal findings

We identified >90 different presenting clinical signs and symptoms in children diagnosed with leukaemia. At time of

Table 2 Signs and symptoms present in more than one-third of children with leukaemia

\begin{tabular}{ll}
\hline Presenting feature & Frequency (\%, pooled proportion) \\
\hline Hepatomegaly & 64 \\
Splenomegaly & 61 \\
Pallor & 54 \\
Fever & 53 \\
Bruising & 52 \\
Infections & 49 \\
Fatigue & 46 \\
Limb pain & 43 \\
Hepatosplenomegaly & 42 \\
Bruising/petechiae & 42 \\
Lymphadenopathy & 41 \\
Bleeding tendency & 38 \\
Rash & 35 \\
\hline
\end{tabular}

all LeUKAemias

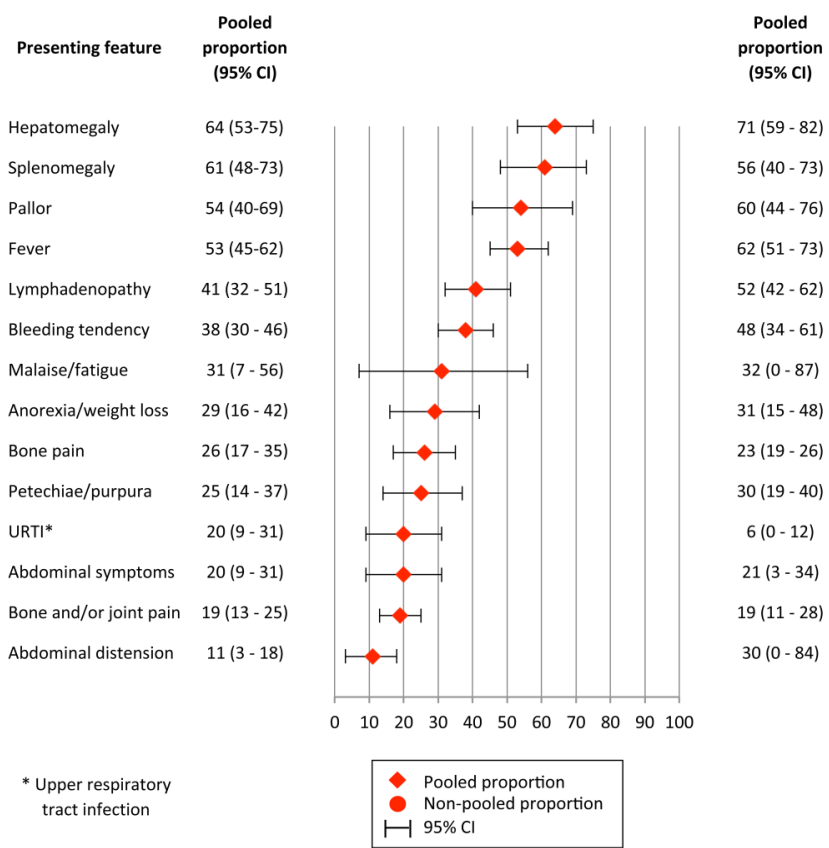

diagnosis, $>50 \%$ of children with leukaemia had palpable livers, palpable spleens, pallor, fever or bruising, concurring with those features identified in current NICE guidance as potential alert symptoms for leukaemia. ${ }^{5}$ Our study also highlights several important potential omissions in NICE guidance. Abdominal symptoms, such as anorexia/weight loss (prevalence $29 \%$ ), abdominal pain (12\%) and abdominal distension (11\%), do not feature in the NICE referral pathway for leukaemia. Nor do some of the haemorrhagic manifestations of leukaemia, such as mucosal bleeding, particularly from gums (25\%). Instead, the guidance highlights only bruising and petechiae. Our results suggest this might be better replaced by 'unusual bleeding' phenomena to include all bleeding manifestations. Finally, although persistent/unexplained bone pain is highlighted in NICE guidance, other musculoskeletal manifestations of leukaemia, such as limp (11\%), joint pain (15\%) and functional impairment $(23 \%)$, are unrepresented.

\section{Strengths and weakness}

This is the first systematic review to describe how leukaemia presents in childhood. It collates data from $>3000$ children in 33 studies from 21 different countries. Our review adhered to rigorous methods, including a systematic search strategy, unrestricted by date or language, and explicit inclusion criteria. ${ }^{46}$ The findings therefore present the most comprehensive and internationally relevant data on presenting features available for clinicians worldwide.

The main limitations of the study reflect deficits in the design and reporting of the included studies. Although studies primarily collected contemporaneous data from medical case notes, all were conducted retrospectively. Given that included studies provided data on cases only, and not on controls, we were unable to determine diagnostic accuracy of clinical features. The high heterogeneity between included studies, which was not accounted for by our a priori subgroup analyses, is unsurprising, given the lack of detail in most studies about how the list of presenting features was derived. Without this, it is difficult to
ACUTE LEUKAEMIAS

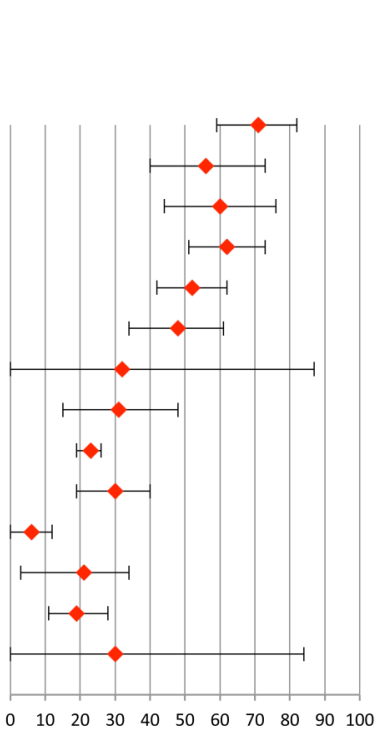

CHRONIC LEUKAEMIAS

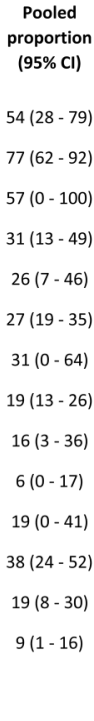

Figure 3 Frequency of signs and symptoms in children according to leukaemia type. 
account for variations between studies in either the number of included features reported (which ranged from 6 to 23) or their frequencies. Additionally, the meta-analysis is complicated by inconsistent, vague or ambiguous language used in individual studies to describe signs and symptoms (such as 'bleeding tendency'). Conversely, some of the terms used clearly overlap to some degree (such as 'bruising', 'bruising/petechiae', 'cutaneous bleeding', 'cutaneous/mucosal bleeding', 'petechiae/purpura', all of which may or may not be identical to 'bleeding tendency' in leukaemia), which contributed to the analyses of an unwieldy 97 different presenting features.

\section{Comparison with existing literature}

Systematic reviews of the presentation of other main childhood cancers (such as central nervous system tumours) have also highlighted gaps in current protocols and guidelines that need to be addressed in updated guidelines. ${ }^{47}$ Qualitative studies indicate that even those symptom lists identified from systematic reviews may be incomplete since they may fail to capture the full range of parent-reported symptoms, in which behavioural and affective changes in children feature prominently. ${ }^{48}$

\section{Implications for practice}

Some of the most commonly presenting features we identified, such as fever, pallor and fatigue, also feature prominently in the presentation of many common, self-limiting diseases of childhood and are therefore unlikely to assist front-line clinicians in discriminating between those children who do or do not have leukaemia. Others-hepatomegaly, splenomegaly, lymphadenopathy and petechiae, for example-are more specific for leukaemia, and hence of greater value as potential red flags. Our findings emphasise the importance, in any child with unexplained illness, of a focused clinical examination that should include abdominal palpation, examining for lymphadenopathy and careful scrutiny of the skin. Abdominal palpation can be particularly challenging in children under 5 years, the peak presenting age group for paediatric leukaemia, but a palpable liver or spleen is an important red flag that should prompt urgent referral for further investigation.

The lack of evidence on combinations of clinical signs and symptoms is disappointing as research in other domains, such as serious infections in children, has shown that combining relatively non-specific features may result in useful prediction rules. ${ }^{49} \mathrm{We}$ suggest that any child presenting with unusual symptom clusters, for example, bruising and fever or limb pain and pallor, should warrant an active search for other corroborative clinical features and consideration of a full blood count and blood film.

\section{Implications for future research}

Our study highlights three key limitations in the current evidence base for how paediatric leukaemia presents, which are priorities for future research in this area. First, we have no data on the frequency and time of onset of symptoms from the point of onset of the first symptoms at home, through to final diagnosis. Second, we do not know how frequently different symptom clusters occur and whether different clusters occur at different time points in the illness trajectory prior to diagnosis. Third, we cannot estimate the diagnostic accuracy of individual or combinations of clinical features as none of the studies included data on control children. Large-scale cohort studies using electronic routine data from primary care and hospital settings would address these gaps, though such studies are likely to be biased towards signs and symptoms already known to have a relation with leukaemia. ${ }^{47}$ An alternative and complementary approach could use qualitative methods to explore patients', parents' and clinicians' accounts of the diagnostic process, generating a richer understanding of the potential determinants of delay.

Acknowledgements The authors gratefully acknowledge the work of Nia Roberts in conducting the literature searches for this review.

Contributors RTC and MJT conceived and designed the study. RTC collected the data, which RTC and MJT analysed. RTC wrote the first draft of the manuscript, and all authors contributed to subsequent drafts. RTC is the guarantor.

Funding This report is independent research arising from a Career Development Fellowship supported by the National Institute for Health Research.

Disclaimer The views expressed in this publication are those of the author(s) and not necessarily those of the NHS, the National Institute for Health Research or the Department of Health.

Competing interests None declared.

Provenance and peer review Not commissioned; externally peer reviewed.

Data sharing statement The following are freely available as supplementary appendices: (1) full search strategy, (2) quality assessment of included studies, (3) signs and symptoms in $<10 \%$ of children and (4) subgroup analyses.

\section{REFERENCES}

1 Stiller CA, Eatock EM. Survival from childhood cancer. In: Siller CA, ed. Childhood cancer in britain: incidence, survival, mortality. Oxford: Oxford University Press, 2007:131-204.

2 American Cancer Society. Cancer facts and figures 2011. Atlanta: American Cancer Society, 2011

3 National Registry of Childhood Tumours/Childhood Cancer Research Group. https:/l www.ccrg.ox.ac.uk. (accessed 24 Apr 2013).

4 Feltbower RG, Lewis IJ, Picton $\mathrm{S}$, et al. Diagnosing childhood cancer in primary care-a realistic expectation? Br J Cancer 2004;90:1882-4.

5 National Institute for Clincal Excellence. Improving outcomes in children and young people with cancer. 2005. http://guidance.nice.org.uk/CSGCYP (accessed 1 Aug 2012).

6 Dang-Tan T, Franco EL. Diagnosis delays in childhood cancer. Cancer 2007; 110:703-13.

7 Department of Health. The NHS Cancer plan: a plan for investment, a plan for reform. 2000. http://www.dh.gov.uk/en/Publicationsandstatistics/Publications/ PublicationsPolicyAndGuidance/DH_4009609 (accessed 12 Oct 2012).

8 Mant J, Nanduri V. Role of the 2-week urgent referral pathway in childhood cancer. Arch Dis Child 2012;97:233-5.

9 Stroup DF, Berlin JA, Morton SC, et al. Meta-analysis of observational studies in epidemiology: a proposal for reporting. JAMA 2000;283:2008-12.

10 von Elm E, Altman DG, Egger $M$, et al. Strengthening the reporting of observational studies in epidemiology (STROBE) statement: guidelines for reporting observational studies. BMJ 2007:335:806-8.

11 Wells GA, Wells B, Shea D, et al. The Newcastle-Ottawa Scale (NOS) for assessing the quality of nonrandomised studies in meta-analyses. Ottowar Hospital Research Institute. http://www.ohri.ca/programs/clinical_epidemiology/oxford.asp (accessed 23 Apr 2013).

12 Case control questions. CASP Appraisal Tools. http://www.sph.nhs.uk/sph-files/ casp-appraisal-tools/Case\%20Control\%2011\%20Questions.pdf/view

13 Cohort 12 questions. CASP Appraisal Tools (cited 078/07/11). http://www.sph.nhs. uk/sph-files/casp-appraisal-tools/cohort\%2012\%20questions.pdf/view

14 Arico M, Bossi G, Schiro R, et al. Juvenile chronic myelogenous leukemia: report of the Italian Registry. Associazione Italiana di Ematologia Oncologia Pediatrica (AIEOP). Haematologica 1993;78:264-9.

15 Arya LS, Bhatia P, Jain Y, et al. Juvenile chronic myelocytic leukemia-report of 10 cases. Med Ped Oncol 1995;241:100-3.

16 Atay $A A$, Kürekçi $A E$, Kesik V, et al. Retrospective analysis of children with acute lymphoblastic leukemia. Gulhane Med J 2005;47:183-6.

17 Bernbeck B, Wüller D, Janssen G, et al. Symptoms of childhood acute lymphoblastic leukemia: red flags to recognize leukemia in daily practice. Klin Padiatr 2009;221:369-73.

18 Biswas S, Chakrabarti S, Chakraborty J, et al. Childhood acute leukemia in West Bengal, India with an emphasis on uncommon clinical features. Asian Pac J Cancer Prev 2009;10:903-6.

19 Castro-Malaspina H, Schaison G, Passe S, et al. Subacute and chronic myelomonocytic leukemia in children (juvenile CML). Clinical and hematologic observations, and identification of prognostic factors. Cancer 1984;54:675-86.

20 Chan KW, Steinherz PG, Miller DR. Acute promyelocytic leukemia in children. Med Pediatr Oncol 1981:9:5-15. 
21 Chang YH, Lu MY, Jou ST, et al. Forty-seven children suffering from chronic myeloid leukemia at a center over a 25-year period. Pediatr Hematol Oncol 2003;20:505-15

22 Chang YH, Jou ST, Lin DT, et al. Differentiating juvenile myelomonocytic leukemia from chronic myeloid leukemia in childhood. J Pediatr Hematol Oncol 2004;26:236-42.

23 Choi SI, Simone JV. Acute nonlymphocytic leukemia in 171 children. Med Pediatr Oncol 1976;2:119-46.

24 da Costa Moraes CA, Trompieri NM, Cavalcante Felix FH. Pediatric acute promyelocytic leukemia: all-transretinoic acid therapy in a Brazilian pediatric hospital. J Pediatr Hematol Oncol 2008;30:387-90.

25 Garcia Calatayud S, San Román Muñoz M, Uyaguari Quezada M, et al. Childhood cancer in the Autonomous Community of Cantabria in Spain (1995-2000). An Pediatr (Barc) 2003;58:121-7.

26 Hasanbegović E. Clinical and hematologic features of pediatric leukemias. Med Arh 2006;60:84-6.

27 Hassan K, Bukhari KP, Zafar A, et al. Acute leukaemia in childrenFrench-American-British (FAB) classification and its relation to clinical features. J Pak Med Assoc 1992;42:29-31.

28 Karimi M, Mehrabani D, Yarmohammadi $\mathrm{H}$, et al. The prevalence of signs and symptoms of childhood leukemia and lymphoma in Fars Province, Southern Iran. Cancer Detect Prev 2008;32:178-83.

29 Klinowska W, Bohdanowicz E, Hein K. Incidence and clinical symptomatology of acute myeloid leukemia in children. Wiad Lek 1973;26:1673-9.

30 La Grutta A, Lo Curto M, Collica F, et al. Clinico-statistical studies of 334 cases of leukemia in childhood. Minerva Pediatr 1980;32:273-82.

31 Ma SK, Chan GC, Ha SY, et al. Clinical presentation, hematologic features and treatment outcome of childhood acute lymphoblastic leukemia: a review of 73 cases in Hong Kong. Hematol Oncol 1997;15:141-9.

32 Meighan SS. Leukemia in children. Incidence, clinical manifestations, and survival in an unselected series. JAMA 1964;190:578-82.

33 Meighan SS. Leukemia in children. Incidence, clinical manifestations, and survival in an unselected series. Cancer 1963;16:656-64.

34 Millot F, Traore P, Guilhot J, et al. Clinical and biological features at diagnosis in 40 children with chronic myeloid leukemia. Pediatrics 2005;116:140-3.

35 Owen $\mathrm{G}$, Lewis IJ, Morgan $\mathrm{M}$, et al. Prognostic factors in juvenile chronic granulocytic leukaemia. Br J Cancer 1992;185:68-71.
36 Paredes-Aguilera R, Romero-Guzman L, Lopez-Santiago N, et al. Biology, clinical, and hematologic features of acute megakaryoblastic leukemia in children. $\mathrm{Am}$ J Hematol 2003;73:71-80.

37 Rajarajeswari G, Viswanathan J. Leukemia in children. A review of 100 cases with typical clinical manifestations. Indian Pediatr 1980;17:37-44.

38 Révész $T$, Kardos $G$, Koós $R$, et al. Acute myeloid leukemia in childhood: 12 years experience of treatment in Hungary. Haematologia (Budap) 1985;18:13-21.

39 Robazzi TC, Barreto JH, Silva LR, et al. Osteoarticular manifestations as initial presentation of acute leukemias in children and adolescents in Bahia, Brazil. J Pediatr Hematol Oncol 2007;29:622-6.

40 Sinigaglia R, Gigante C, Bisinella $G$, et al. Musculoskeletal manifestations in pediatric acute leukemia. J Pediatr Orthop 2008;28:20-8.

41 Thulesius H, Pola J, Håkansson A. Diagnostic delay in pediatric malignancies-a population-based study. Acta Oncol 2000;39:873-6.

42 Zahid M, Khalid A, Ahmed ZD, et al. Acute leukemias of childhood: a retrospective analysis of 62 cases. J Pak Med Assoc 1996:46:147-9.

43 Das KV, Aboobacker CM, Mathew 0. Clinical presentation of leukemias in children in south Kerala. Indian Pediatr 1974;11:431-8.

44 Drozynsky M, Hering D, Rückemann K, et al. Acute lymphoblastic leukemia in children: Analysis of the initial clinical features and laboratory findings. Annales Academiae Medicae Gedanensis 2002:32:111-7.

45 Liu Z, Song H, Chen L. Clinical features of 12 children with acute myeloid leukemia. J Leukemia and Lymphoma 2010;19:661-5.

46 Preferred Reporting Items for Systematic Reviews and Meta-Analyses (PRISMA) Statement. http://www.prisma-statement.org/ (accessed 23 Apr 2013).

47 Wilne SK, Collier J, Kennedy C, et al. Presentation of childhood CNS tumours: a systematic review and meta-analysis. Lancet Oncol 2007;8:685-95.

48 Dixon-Woods M, Findlay M, Young B, et al. Parents' accounts of obtaining a diagnosis of childhood cancer. Lancet 2001;357:670-4.

49 Van den Bruel A, Haj-Hassan T, Thompson M, et al. Diagnostic value of clinical features at presentation to identify serious infection in children in developed countries: a systematic review. Lancet 2012;6:834-45.

50 Dommett RM, Redaniel MT, Stevens MC, et al. Features of childhood cancer in primary care: a population-based nested case-control study. Br J Cancer 2012;106:982-7 